\title{
Influences on Adherence to Diet and Physical Activity Recommendations in Women and Children: Insights from Six European Studies
}

\author{
Hazel Inskip ${ }^{a} \quad$ Janis Baird ${ }^{a} \quad$ Mary Barker $^{a} \quad$ Annette L. Briley ${ }^{c}$ \\ Stefania D'Angelo ${ }^{a}$ Veit Grote ${ }^{g}$ Berthold Koletzko ${ }^{g}$ Wendy Lawrence ${ }^{a, b}$ \\ Yannis Manios $^{\text {e George Moschonis }}{ }^{\mathrm{e}}$ George P. Chrousos ${ }^{d, f}$ Lucilla Poston ${ }^{c}$ \\ Keith Godfrey ${ }^{a, b}$ \\ ${ }^{a}$ MRC Lifecourse Epidemiology Unit, University of Southampton, Southampton General Hospital, and ${ }^{\text {b NIHR }}$ \\ Southampton Biomedical Research Centre, University Hospital Southampton NHS Foundation Trust and University \\ of Southampton, Southampton, and 'KCL Division of Women's Health, Women's Health Academic Centre, King's

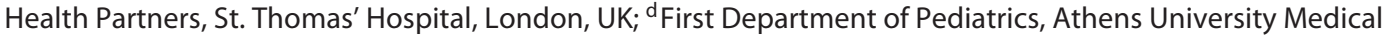 \\ School, Aghia Sophia Children's Hospital, and ' Department of Nutrition and Dietetics, Harokopio University of \\ Athens, Athens, Greece; ${ }^{f}$ King Abdulaziz University, Jeddah, Saudi Arabia; 9 Division of Metabolic and Nutritional \\ Medicine, Dr. von Hauner Children's Hospital, Klinikum der Universität München, Munich, Germany
}

\section{Key Words}

Children · Diet · Physical activity · Pregnancy $\cdot$ Women

\begin{abstract}
Background: Across Europe, poor health behaviours are associated with increased risks of non-communicable diseases. There is particular concern about young women, children and families, not least as health behaviours operating before and during pregnancy and in early postnatal life may have profound long-term consequences for children's health. Using findings drawn from 7 European countries, we aimed to identify barriers to the implementation and uptake of dietary and physical activity recommendations, and to consider how best to achieve changes in mothers' behaviours and thereby improve the adoption of health recommendations.
\end{abstract}

Six studies across the 7 countries were used for this narrative synthesis of findings. Key Messages: A woman's education has a strong influence on her own and her children's health behaviours. Women's diets vary across ethnic groups and according to number of children, but psychological factors, such as self-efficacy and sense of control, which may be amenable to modification, are powerful, too, particularly in women with lower educational attainment. Maternal influences on children's behaviours are strong. Differences exist in infant feeding across countries, and there are apparent urban/ rural differences in children's diets and physical activity. Conclusions: Interventions are needed before, as well as during, pregnancy to improve the diets of families with young children. Interventions to address psychological barriers to eating well and being more active are indicated.

(c) 2014 S. Karger AG, Basel

\section{KARGER}

E-Mail karger@karger.com

www.karger.com/anm
(C) 2014 S. Karger AG, Basel

0250-6807/14/0644-0332\$39.50/0
Hazel Inskip

MRC Lifecourse Epidemiology Unit, University of Southampton

Southampton General Hospital

Southampton SO16 6YD (UK)

E-Mailhmi@mrc.soton.ac.uk 


\section{Introduction}

Nutrition during early development impacts on later health, and there is an increasing focus on the health behaviours of women and children. In 2007, the Commission of European Communities set out a strategy for nutrition-, overweight- and obesity-related health issues in which it noted the deterioration of dietary quality and physical activity over previous decades and its relationship with increased risks of non-communicable diseases [1]. Health behaviours that lead to poorer growth, development and health are difficult to modify and, while advice and recommendations abound, the uptake by individuals is still not optimal. For example, the UK National Diet and Nutrition Survey has shown that few groups adhere to the recommendations for fruit and vegetable consumption, and the proportion of individuals achieving the recommended levels is still low [2].

As part of the EarlyNutrition programme [3], we conducted a narrative synthesis of findings from 6 studies. We aimed to identify barriers to the implementation and uptake of dietary and physical activity recommendations in women and children. Specifically, we sought to identify behavioural and lifestyle influences on adherence to current dietary and physical activity recommendations, and maternal influences on the child's diet and physical activity. We examined similarities and differences between the main influences on diet, dietary behaviours and physical activity across 6 studies in 7 European countries.

\section{Methods}

One cohort study, 3 intervention studies and 2 cross-sectional studies were included in this narrative. The studies have been described elsewhere and the references provide full details. Brief summaries are as follows.

\section{Cohort Study}

The Southampton Women's Survey (SWS) [4] is a study of 12,583 Southampton women in the UK aged 20-34 years who were assessed when they were not pregnant; 3,158 of these women were followed through a subsequent pregnancy and the children were followed through infancy and childhood. Information on diet was obtained before and during pregnancy and during infancy and childhood. Objective information on physical activity from Actiheart measurements (Cambridge Neurotechnology Ltd., Papworth, UK) was obtained on a subset of mothers and children when the children were 4 years of age.

Intervention Studies

UPBEAT $[5,6]$ is a multicentre randomised controlled trial comparing a behavioural intervention designed to improve glycaemic control with standard antenatal care in obese pregnant women.
Women with a body mass index (BMI) $\geq 30$ and a singleton pregnancy between $\geq 15$ weeks and $<19$ weeks' gestation are eligible, unless they have pre-defined, pre-existing diseases. The behavioural intervention is delivered by a health trainer over 8 group sessions. Dietary data from the pilot study of 183 women have been used here [6].

The Childhood Obesity Project (CHOP) [7] is a double-blind, randomised controlled trial of 636 children randomised to 2 groups fed 2 types (standard and follow-on) of cow's milk-based formula with either a lower or a higher protein content for the first year of life. Additionally, an observational group of 298 exclusively breast-fed children was included. Children were recruited in 5 countries (Belgium, Germany, Italy, Poland and Spain). Infants were enrolled during the first 8 weeks of life. Information was available on the diets of the infants at 6 months of age.

The Southampton Initiative for Health (SIH) [8] is a beforeand-after controlled trial of an intervention introduced in Children's Centres in Southampton, UK. The intervention aimed to increase the self-efficacy and perceived control, and through this the diet and physical activity levels, of women attending Sure Start Children's Centres, by training Children's Centre staff in skills to support behaviour changes. The diets and physical activity levels of 527 women in Southampton (intervention area) and 495 women in Gosport and Havant (a demographically similar control area) were assessed before the training intervention began, and these data were used in this analysis.

\section{Cross-Sectional Studies}

The Growth, Exercise and Nutrition Epidemiological Study (GENESIS) [9] aimed to evaluate the food and nutrient intakes and growth and development of a representative sample of Greek toddlers and pre-school children. Boys $(n=1,218)$ and girls $(n=$ 1,156 ) aged $1-5$ years, stratified by parental educational level, were examined from 105 nurseries. Demographic, lifestyle, physical activity, dietary and anthropometry data were recorded.

The Nutwell study $[10,11]$ investigated the relationship between educational attainment and specific psychological variables and the quality of the diet in 372 women living in Southampton, UK, and attending, over a 6-month period, children's play sessions and baby clinics run by Sure Start Children's Centres in the city. Data were collected using a structured questionnaire.

\section{Analytical Methods}

The outcomes considered for the 6 studies, where available, were: dietary quality, fruit and vegetable consumption, glycaemic load, breast-feeding initiation and duration, complementary feeding at 6 months and physical activity. The influences on these outcomes that were considered included ethnicity, level of educational attainment, socioeconomic position, household income, receipt of benefits, deprivation, maternal age, household composition, psychological factors, BMI and smoking. For analyses of children, parity/birth order and the child's gender were considered. Four target groups were identified for these analyses, i.e. non-pregnant women, pregnant women, infants and children up to age 5 years.

A narrative synthesis of the published findings from the studies was conducted. The contributions of the various studies to the particular components of the narrative are given in table 1. For assessment of dietary quality, 3 studies used principal component analysis and then considered the major principal components as measures of diet quality. Other studies used the Healthy Eating Index [12] or an adaptation for use in pregnancy $[13,14]$. 
Table 1. Contribution of studies to the different components of the synthesis of findings

\begin{tabular}{|c|c|c|c|c|c|c|}
\hline \multirow[t]{2}{*}{ Studies $^{\mathrm{a}}$} & \multicolumn{2}{|c|}{$\begin{array}{l}\text { Non-pregnant } \\
\text { women }\end{array}$} & \multirow{2}{*}{$\begin{array}{l}\text { Pregnant } \\
\text { women } \\
\text { diet }\end{array}$} & \multirow{2}{*}{$\begin{array}{l}\text { Infants } \\
\text { diet }\end{array}$} & \multicolumn{2}{|c|}{ Children } \\
\hline & diet & $\mathrm{PA}$ & & & diet & PA \\
\hline \multicolumn{7}{|l|}{ Cohort study } \\
\hline SWS & $\checkmark$ & $\checkmark$ & $\checkmark$ & $\checkmark$ & $\checkmark$ & $\checkmark$ \\
\hline \multicolumn{7}{|c|}{ Intervention studies } \\
\hline UPBEAT & & & $\checkmark$ & & & \\
\hline $\mathrm{CHOP}$ & & & & $\checkmark$ & & \\
\hline $\mathrm{SIH}$ & $\checkmark$ & & & & $\sqrt{ }$ & \\
\hline \multicolumn{7}{|c|}{ Cross-sectional studies } \\
\hline GENESIS & & & & $\checkmark$ & $\checkmark$ & $\checkmark$ \\
\hline Nutwell & $\checkmark$ & & & & & \\
\hline
\end{tabular}

$\mathrm{PA}=$ Physical activity. ${ }^{\mathrm{a}}$ Full study names and details are given in the text.

\section{Focus Groups}

Focus groups conducted in Southampton aimed to explore lifestyle and other factors that influenced the food choices of young women with differing educational attainment and how these women could best be supported to improve their food choices. Eleven focus group discussions were held in total: 8 with women of lower educational attainment ( 42 women) and 3 with women of higher educational attainment [14]. All women were white Caucasians.

Transcripts of the audio recordings of the discussions were read and re-read and subjected to a thematic analysis. Comments from participants were coded under pre-defined and emerging themes using a constant comparative method [15]. A further analysis was conducted of data from 4 focus groups, i.e. 2 from each of the lower and higher educational attainment groups [16], to examine the concept of food involvement and its influence on the way women feed themselves and their children. Food involvement indicates the level of importance of food in a person's life. Five pre-defined areas of food involvement, i.e. acquisition, preparation, cooking, eating and disposal of food, were explored [17].

\section{Results}

\section{Non-Pregnant Women}

Dietary Quality

Data from the SWS, the SIH and Nutwell contributed to these analyses. All 3 studies used a dietary quality measure known as a 'prudent diet score' in full form [18] or an abridged version based on 20 food items [19]. Higher scores indicate greater conformity with healthy-eating recommendations. The prudent diet score was strongly positively associated with the women's educational attainment [18]. Women without children tended to have higher scores than parous women, as did older women, even after adjustment for education. Clustering of poor health behaviours was evident, with women who smoked and exercise less also having poorer quality diets. A woman's sense of control was strongly positively associated with her dietary quality, but the effect was confined to women with lower levels of educational attainment [11]. The education effect was partly mediated by the woman's food involvement. In women with lower educational attainment, self-efficacy was also associated with dietary quality, but this was largely mediated by perceived control and food involvement. Furthermore, diets were found to be of poorer quality in those with a more negative affect, suggesting that mood plays a role in dietary quality [17].

\section{Physical Activity}

In the SWS, among mothers who wore Actiheart monitors, BMI and working full time were positively associated with average sedentary time, while there was a negative association with duration of schooling. Conversely, a lower BMI and not being at work were associated with light physical activity. Having more than one younger child at home was positively associated with the mothers' average daily light physical activity, but there were no significant associations with moderate or vigorous physical activity [20].

\section{Pregnant Women}

Dietary Quality

In the SWS, the women's prudent diet scores changed little from before pregnancy to during pregnancy $[21,22]$. Not surprisingly, the influences on the score in pregnancy were similar to those seen for the non-pregnant women, described above.

\section{Glycaemic Load}

The UPBEAT pilot trial examined differences between obese pregnant women who were allocated to intervention or control arms of the study. The intervention provided behaviour change support and recommendations, with feedback on progress. Reductions in the glycaemic load were seen in women in the intervention arm, indicating that support for changing behaviour has a beneficial effect on the diets of such women during pregnancy [6]. 


\section{Infants}

Breast-Feeding

In GENESIS, CHOP and the SWS, mothers with higher pre-pregnancy maternal BMI, lower educational attainment, smoking in pregnancy and multiparity were less likely to breast-feed their infants [7, 23, 24]. In GENESIS, mothers of premature babies ( $<37$ weeks' gestation) were less likely to initiate breast-feeding [23] and in both the SWS and GENESIS a shorter duration of breast-feeding was found in women who were either underweight before pregnancy or had a lower BMI or smoked during pregnancy $[23,24]$. In GENESIS, multiparous women breast-fed their children for about 7 weeks less than uniparous women [23].

\section{Introduction of Solid Food}

In the CHOP study, the median age of introduction of solid food was 19 weeks, with almost all children (97\%) taking solids by 6 months [25]. Solids tended to be introduced earliest in Poland and the latest in Germany (91 vs. $66 \%$ introduced by 22 weeks of age). Boys were introduced to solids earlier than girls (also reported in the SWS) [26], as were infants born to less well-educated parents or to mothers who smoked in pregnancy. Formulafed infants and those with a higher birth weight or born to mothers with a higher BMI tended to start eating solid food at a younger age.

\section{Quality of Infant Diets}

Although half of all complementary foods in the CHOP trial came from commercial infant food (CIF) sources, there were major differences among the different European countries in the quantity of the CIF consumed; parents in Germany reported $>90 \%$ of complementary food from CIF, while those in Belgium reported $<10 \%$. A higher proportion of formula-fed infants received CIF during the first year of life compared with those who were breast-fed [27]. There were also considerable differences between countries and between breast-fed and formulafed children in terms of intakes of energy-providing liquids, such as sugared teas and fruit juices; for example, during the first year of life, instant teas were consumed by $70-88 \%$ of formula-fed infants in Poland compared with $<5 \%$ in Belgium [28].

Within the SWS, infant dietary quality scores at 6 and 12 months of age were derived in a similar way to the prudent diet scores used for the mothers' data [29]. They were named 'infant guidelines scores', as they indicated the extent to which mothers followed the current infant feeding recommendations. The strongest predictor of

Influences on Health Behaviours of Women and Children the scores at both 6 and 12 months was the mother's prudent diet score before she became pregnant. The mother's educational attainment was also strongly positively associated with the infant guidelines score, but a negative association was seen with birth order. At 6 but not 12 months, the infant guidelines score increased with maternal age, decreased with increasing maternal $\mathrm{BMI}$ and was lower for infants whose mothers smoked [29].

\section{Children}

Diet Quality

In the GENESIS study, $80 \%$ of participants aged $2-5$ years had a Healthy Eating Index score $<50$, indicating a poor diet. Scores were significantly higher among boys, children aged 4-5 years, those who participated in moderate-to-vigorous physical activities for more than $3 \mathrm{~h} /$ week, those who lived in rural or small towns and those whose mothers were employed or had more years of education [30].

In the SWS, the key influence on the quality of the children's diets at age 3 years was the quality of their mothers' diets before pregnancy (the prudent diet score); alone, it accounted for almost a third of the variance in the child's dietary quality [31]. There were no gender differences in diet quality. Better-quality diets were more common in children of mothers with higher educational attainment who lived in a less-deprived area, had a lower BMI and were non-smokers. Children who were of a lower birth order, spent less time watching TV per day or ate more meals (in comparison with nibbling throughout the day) were also more likely to have a more prudent $\operatorname{diet}[31]$.

\section{Fruit and Vegetable Consumption}

In the GENESIS study, few associations were found with vegetable consumption in the children. Among those aged 1-3 years, boys tended to be less likely to achieve the recommended intake than girls, while in children aged 3-5 years 'urban' dwelling children were less likely to meet the recommended intake than those living in 'large urban' areas. Children born to mothers who were smokers during the time they breast-fed the children were less likely to meet the recommendations.

There were inconsistent relationships between fruit consumption and the type of area of residence: compared with those living in large urban areas, children aged 1-3 years living in urban areas were less likely to achieve the recommended fruit intake, whereas children aged 3-5 years in urban areas were more likely to do so. Also in 
those aged 3-5 years, those living in rural areas were more likely to meet the recommendations, but there was no evidence for this in the younger age group. In both age groups, there was a suggestion that those children whose mothers had been exposed to cigarette smoke in pregnancy were less likely to eat sufficient fruit. Children aged 1-3 years were more likely to achieve the recommended intake if their mothers were more highly educated, whereas for children aged 3-5 years those born premature $(<37$ weeks' gestation) were more likely to meet the recommendations than those born at term.

\section{Physical Activity}

In the GENESIS study, in both age groups (1-3 and 3-5 years), compared with a baseline group of those living in large urban areas, children living in 'small towns' and 'rural' areas were more likely to meet physical activity recommendations, but those in urban areas were less likely to meet them. Also, women who took folic acid during pregnancy were less likely to have active children than those who did not. In those aged 1-3 years, boys were more active than girls, and those whose mothers were of normal weight before pregnancy were more active than those with overweight or obese mothers. In the 3- to 5 -year age group, children born to mothers who had gestational diabetes were more active, possibly indicating that these mothers became more health conscious following the diagnosis of diabetes and so encouraged their children to be more active.

Objective measurements of physical activity were made in 593 SWS children at age 4 years [32] using an Actiheart monitor. On average, children were active for two thirds of each day, but nearly $90 \%$ of the active time was spent on light physical activity. There were no differences in the children's average daily levels of sedentary and light physical activity by temporal and demographic factors, but differences emerged when the activity was segmented across the day. Sex differences were largest in the morning, with girls being more sedentary and less active than boys. Children were more sedentary and less active in the morning if they attended childcare full-time compared with part-time, and on weekend mornings compared to weekdays. The reverse was true for weekend afternoons and evenings. Children with more educated mothers were less active in the evenings. During summer rather than winter evenings, children were less sedentary and did more moderate or vigorous activity [32]. Children's and mothers' activity levels were positively associated at all activity intensities [20].
Focus Groups Discussions with Women of Lower and Higher Educational Attainment

The aim of these focus groups was to explore the differences between women of lower and higher educational attainment in relation to influences on their diets [17]. The key theme underlying the focus group discussions with women of lower educational attainment was their sense that they lacked control over food choices for themselves and their families, with partners and children giving them little support for making healthy food choices and exerting a high degree of control. Healthy food was perceived to be expensive and they felt they could not afford to buy food that might not be eaten. Having limited skill and experience with food further undermined the ability of these women to feed their families as they felt they should. Women of higher educational attainment felt far more in control, received more social support, were less constrained by the environment in which they lived and tended to have a greater store of skills and experience with food than women of lower educational attainment. There were also clear differences in their level of food involvement, demonstrated by the way they spoke about cooking and eating. Women of lower educational attainment spoke almost entirely about the importance of feeding their children and partners and appeared to demonstrate a lower overall food involvement largely because they were generally less interested in eating and cooking for themselves, compared with women of higher educational attainment. This did not appear to apply to cooking for their families, to which they gave a higher priority. Women of higher educational attainment, on the other hand, described engagement in cooking and eating for themselves as much as for their partners and children.

\section{Discussion}

It is apparent that older women and those with higher educational attainment have better diets for themselves and for their children. Children's diets appear to be highly influenced by those of their mothers and indeed reflect their mothers' diets before the children were even conceived. Women who smoked had poorer-quality diets before and during pregnancy, and so did their children. Living in more disadvantaged circumstances was associated with poorer diets, and mothers in such circumstances appeared to have lower levels of food involvement.

Infant feeding practices varied considerably between different countries in Europe, with infants in some countries being fed little in the way of commercial foods, while 
in others such foods are used extensively. Within Greece, there appeared to be differences in both physical activity levels and fruit and vegetable consumption between children living in large urban versus rural areas or small towns. Compared with children in large urban areas, those in rural areas tended to be more likely to achieve recommendations, but for those in urban areas the findings were more mixed.

Both the quantitative and qualitative work in the UK showed that psychological factors in the women appeared to influence their and their children's diets. Women with a greater sense of control and who had higher levels of food involvement were empowered to eat more healthily and to feed their children better.

\section{Strengths and Weaknesses}

Data from 7 European Union countries contributed to these analyses. Differences in the diets of the children were seen between the countries, but the data on women, both non-pregnant and pregnant, come solely from the UK, making it hard to generalise the findings. Uniquely, the SWS allowed influences to be tracked from before conception. The UPBEAT trial provided insights into the behaviours of pregnant women who are obese, while the $\mathrm{SIH}$ and Nutwell examined the psychological influences on health behaviours. The CHOP study provided comparisons across national boundaries, while GENESIS gave greater insights into the diets and lifestyles of young children and could be compared with the SWS. The GENESIS study also allowed comparisons between those living in various types of areas of residence.

\section{Pointers for the Development of Interventions}

Education is clearly associated with better health behaviours, but while improved educational attainment is a worthy goal, this is challenging to implement. Other influences such as the age and parity of the mother cannot be modified. However, empowering mothers to improve their sense of control and self-efficacy is indicated. The UPBEAT pilot trial showed promising results of an approach to improve psychological factors, and similar methods were used in the SIH. The SWS has shown that diets in women track from before pregnancy and influence their children's diets, pointing to interventions that operate before pregnancy. This suggests that greater effort should be invested in accessing groups of women preconceptionally, however challenging this is, since investment in this phase of the life course would appear to pay dividends. School-based interventions aimed at adolescents offer scope for this [33], though for most school students, child-bearing will be many years hence. Interventions during pregnancy or targeting families with young children is also important if the cycle of poor health behaviours across generations is to be broken.

The variation seen in infant feeding across countries in the European Union is of interest, but insights from this work are limited to certain aspects of feeding. A greater uptake and longer duration of breast-feeding are strongly encouraged already. The urban/rural differences noted in GENESIS may point to interventions in relation to the physical environment. Extending some of the singlecountry work to other countries would be informative.

Future work within the studies described here will add to the evidence base. The SWS and CHOP studies are continuing follow-ups of the children at older ages, and further analyses of the GENESIS study are being conducted. In Southampton, additional focus groups with mothers of young children have been conducted and are being analysed. Also, 2 new intervention studies have commenced, i.e. one in pregnant women, incorporating the behaviour change approaches used in the SIH, and another aimed at improving health behaviours in teenagers before they embark on having their own children. The UPBEAT trial has completed recruitment, and the results of the full trial will provide extensive information on a behaviour change intervention in obese pregnant women; follow-up of the infants will provide insights into the impact of the intervention on infant feeding and the infants' health, development and body composition.

\section{Acknowledgements}

This work was funded as part of the European Union's 7th Framework Programme (FP7/2007-2013), EarlyNutrition project, under grant agreement No. 289346. The work within the SWS, the SIH and Nutwell received funding from the UK Medical Research Council. The SWS was additionally funded by the British Heart Foundation and the Dunhill Medical Trust, and both the SIH and the SWS were funded by the NIHR Southampton Biomedical Research Centre. Additional funding for Nutwell came from an award from Danone Institute International. The UPBEAT study was funded by the National Institute for Health Research (NIHR) (UK) under the Programme Grants for Applied Research programme (RP-0407-10452). L.P. and A.L.B. are supported by Tommy's Charity, UK. The GENESIS study was supported by a research grant from Friesland Foods Hellas. The CHOP study was supported by the Commission of the European Community, specifically the RTD programme Quality of Life and Management of Living Resources, within the 5th Framework Programme, research grant No. QLRT-2001-00389 and QLK1-CT-2002-30582, and the 6th Framework Programme, contract No. 007036, and the Euro- 
pean Union's 7th Framework Programme (FP7/2007-2013), EarlyNutrition project, under grant agreement No. 289346. The formula for this study was produced by Bledina (Villefranche-surSaône Cédex, France, part of Danone Baby Nutrition), who operated as a partner of this European Union project and received a grant from the European Union Commission for this task.

This paper does not necessarily reflect the views of the Commission of the European Community or other policy makers and in no way anticipates the future policy in this area.

\section{Disclosure Statement}

No funding bodies had any role in study design, data collection and analysis, decision to publish, or preparation of this paper. K.G. and L.P. have received reimbursement for speaking at conferences sponsored by companies selling nutritional products, and are part of an academic consortium that has received research funding from Abbott Nutrition, Nestec and Danone.

\section{References}

1 Commission of the European Communities: A strategy for Europe on nutrition, overweight and obesity-related health issues. 2007. http://ec.europa.eu/health/nutrition physical_activity/policy/index_en.htm (accessed April 7, 2014).

2 Department of Health: UK National Diet and Nutrition Survey. 2014. http://webarchive. nationalarchives.gov.uk/20130402145952/ http://transparency.dh.gov.uk/category/statistics/ndns/ (accessed April 7, 2014).

3 Koletzko B, Brands B, Poston L, Godfrey K, Demmelmair H: Early nutrition programming of long-term health. Proc Nutr Soc 2012;71:371-378.

-4 Inskip HM, Godfrey KM, Robinson SM, Law CM, Barker DJ, Cooper C; SWS Study Group: Cohort profile: the Southampton Women's Survey. Int J Epidemiol 2006;35:42-48.

5 Briley AL, Barr S, Badger S, Bell R, Croker H, Godfrey KM, Holmes B, Kinnunen TI, Nelson SM, Oteng-Ntim E, Patel N, Robson SC, Sandall J, Sanders T, Sattar N, Seed PT, Wardle J, Poston L: A complex intervention to improve pregnancy outcome in obese women: the UPBEAT randomised controlled trial. BMC Pregnancy Childbirth 2014;14:74.

-6 Poston L, Briley AL, Barr S, Bell R, Croker H, Coxon K, Essex HN, Hunt C, Hayes L, Howard LM, Khazaezadeh N, Kinnunen T, Nelson SM, Oteng-Ntim E, Robson SC, Sattar N, Seed PT, Wardle J, Sanders TA, Sandall J: Developing a complex intervention for diet and activity behaviour change in obese pregnant women (the UPBEAT trial): assessment of behavioural change and process evaluation in a pilot randomised controlled trial. BMC Pregnancy Childbirth 2013;13:148.

7 Koletzko B, von Kries R, Closa R, Escribano J, Scaglioni S, Giovannini M, Beyer J, Demmelmair H, Gruszfeld D, Dobrzanska A, Sengier A, Langhendries JP, Rolland Cachera MF, Grote V; European Childhood Obesity Trial Study Group: Lower protein in infant formula is associated with lower weight up to age 2 y: a randomized clinical trial. Am J Clin Nutr 2009;89:1836-1845.

\section{Barker M, Baird J, Lawrence W, Jarman M, Black C, Barnard K, Cradock S, Davies J, Mar- getts B, Inskip H, Cooper C: The Southamp- ton Initiative for Health: a complex interven- tion to improve the diets and increase the physical activity levels of women from disad- vantaged communities. J Health Psychol 2011;16:178-191.}

-9 Manios Y: Design and descriptive results of the 'Growth, Exercise and Nutrition Epidemiological Study In preSchoolers': the GENESIS study. BMC Public Health 2006;6:32.

10 Barker M, Lawrence W, Crozier S, Robinson S, Baird J, Margetts B, Cooper C; Food Choice Group, University of Southampton: Educational attainment, perceived control and the quality of women's diets. Appetite 2009;52: 631-636.

11 Lawrence W, Schlotz W, Crozier S, Skinner TC, Haslam C, Robinson S, Inskip H, Cooper C, Barker M; Food Choice Group, University of Southampton: Specific psychological variables predict quality of diet in women of lower, but not higher, educational attainment. Appetite 2011;56:46-52.

-12 Kennedy ET, Ohls J, Carlson S, Fleming K: The Healthy Eating Index: design and applications. J Am Diet Assoc 1995;95:1103-1108.

$\checkmark 13$ McCullough ML, Willett WC: Evaluating adherence to recommended diets in adults: the Alternate Healthy Eating Index. Public Health Nutr 2006;9:152-157.

14 Rifas-Shiman SL, Rich-Edwards JW, Kleinman KP, Oken E, Gillman MW: Dietary quality during pregnancy varies by maternal characteristics in Project Viva: a US cohort. J Am Diet Assoc 2009;109:1004-1011.

15 Boyatzis RE: Transforming Qualitative Information: Thematic Analysis and Code Development. Thousand Oaks, Sage, 1998.

16 Lawrence W, Skinner C, Haslam C, Robinson S, Inskip H, Barker D, Cooper C, Jackson A, Barker M: Why women of lower educational attainment struggle to make healthier food choices: the importance of psychological and social factors. Psychol Health 2009;24:10031020 .
17 Jarman M, Lawrence W, Ntani G, Tinati T, Pease A, Black C, Baird J, Barker M; SIH Study Group: Low levels of food involvement and negative affect reduce the quality of diet in women of lower educational attainment. J Hum Nutr Diet 2012;25:444-452.

18 Robinson SM, Crozier SR, Borland SE, Hammond J, Barker DJ, Inskip HM: Impact of educational attainment on the quality of young women's diets. Eur J Clin Nutr 2004;58:11741180.

19 Crozier SR, Inskip HM, Barker ME, Lawrence WT, Cooper C, Robinson SM; SWS Study Group: Development of a 20 -item food frequency questionnaire to assess a 'prudent' dietary pattern among young women in Southampton. Eur J Clin Nutr 2010;64:99-104.

20 Hesketh KR, Goodfellow L, Ekelund U, McMinn AM, Godfrey KM, Inskip HM, Cooper C, Harvey NC, van Sluijs EM: Activity levels in mothers and their preschool children. Pediatrics 2014;133:e973-e980.

21 Crozier SR, Robinson SM, Godfrey KM, Cooper C, Inskip HM: Women's dietary patterns change little from before to during pregnancy. J Nutr 2009;139:1956-1963.

22 Crozier SR, Robinson SM, Borland SE, Godfrey KM, Cooper C, Inskip HM; SWS Study Group: Do women change their health behaviours in pregnancy? Findings from the Southampton Women's Survey. Paediatr Perinat Epidemiol 2009;23:446-453.

23 Manios Y, Grammatikaki E, Kondaki K, Ioannou E, Anastasiadou A, Birbilis M: The effect of maternal obesity on initiation and duration of breast-feeding in Greece: the GENESIS study. Public Health Nutr 2009;12:517-524.

24 Fisk CM, Crozier SR, Inskip HM, Godfrey KM, Cooper C, Roberts GC, Robinson SM; Southampton Women's Survey Study Group: Breastfeeding and reported morbidity during infancy: findings from the Southampton Women's Survey. Matern Child Nutr 2011;7: 61-70. 
25 Grote V, Schiess SA, Closa-Monasterolo R, Escribano J, Giovannini M, Scaglioni S, Stolarczyk A, Gruszfeld D, Hoyos J, Poncelet P, Xhonneux A, Langhendries JP, Koletzko B; European Childhood Obesity Trial Study Group: The introduction of solid food and growth in the first $2 \mathrm{y}$ of life in formula-fed children: analysis of data from a European cohort study. Am J Clin Nutr 2011;94:1785S1793S.

26 Robinson SM, Marriott LD, Crozier SR, Harvey $\mathrm{NC}$, Gale CR, Inskip HM, Baird J, Law CM, Godfrey KM, Cooper C; Southampton Women's Survey Study Group: Variations in infant feeding practice are associated with body composition in childhood: a prospective cohort study. J Clin Endocrinol Metab 2009; 94:2799-2805.

-27 Schiess S, Grote V, Scaglioni S, Luque V, Martin F, Stolarczyk A, Vecchi F, Koletzko B; European Childhood Obesity Project: Introduction of complementary feeding in 5 European countries. J Pediatr Gastroenterol Nutr 2010; 50:92-98.
28 Schiess SA, Grote V, Scaglioni S, Luque V, Martin F, Stolarczyk A, Vecchi F, Koletzko B; European Childhood Obesity Project: Intake of energy providing liquids during the first year of life in five European countries. Clin Nutr 2010;29:726-732.

29 Robinson S, Marriott L, Poole J, Crozier S, Borland S, Lawrence W, Law C, Godfrey K, Cooper C, Inskip H; Southampton Women's Survey Study Group: Dietary patterns in infancy: the importance of maternal and family influences on feeding practice. Br J Nutr 2007; 98:1029-1037.

30 Manios Y, Kourlaba G, Kondaki K, Grammatikaki E, Birbilis M, Oikonomou E, RomaGiannikou E: Diet quality of preschoolers in Greece based on the Healthy Eating Index: the GENESIS study. J Am Diet Assoc 2009; 109: 616-623.
1 Fisk CM, Crozier SR, Inskip HM, Godfrey KM, Cooper C, Robinson SM; Southampton Women's Survey Study Group: Influences on the quality of young children's diets: the importance of maternal food choices. Br J Nutr 2011;105:287-296.

32 Hesketh KR, McMinn AM, Ekelund U, Sharp SJ, Collings PJ, Harvey NC, Godfrey KM, Inskip HM, Cooper C, van Sluijs EM: Objectively measured physical activity in four-year-old British children: a cross-sectional analysis of activity patterns segmented across the day. Int J Behav Nutr Phys Act 2014;11:1.

33 Grace M, Woods-Townsend K, Griffiths J, Godfrey K, Hanson M, Galloway I, Azaola MC, Harman K, Byrne J, Inskip H: A sciencebased approach to developing teenagers' views on their health and the health of their future children. Health Educ 2012;112:543559. 